\title{
A Study between Malnutrition Associated with Malocclusion, Dental Caries, Enamel Hypoplasia and Salivary Gland Flow in Mixed Dentition Stage - An in Vivo Study
}

\author{
Dr.Joshi Kaushal ${ }^{1}$,Dr.Arora Vivek ${ }^{2}$,Dr.Arora Ruchi ${ }^{2}$,Dr.Dogra Subha ${ }^{2}$ \\ ${ }^{I}$ (Darshan Dental College, Udaipur, Rajasthan, India)
}

\begin{abstract}
Malnutrition in Indian population is recently becoming subject of study. The purpose of this study was to evaluate the hypothesis of malnutrition associated with malocclusion and other oral anomalies.

Aim: Aim of this study was to evaluate the association of malnutrition with malocclusion, dental caries, enamel hypoplasia and salivary flow in mixed dentition stage.

Material and method: One hundred twenty subjects were selected for this study in Rabindranath Tagore Medical College \& hospital, Udaipur, Rajasthan. BMI index was calculated and oral examinations were done to evaluate all findings.

Result: In the present study, there was no significant relationship found in malnutrition with dental crowding ( $P$ value $=0.79)$, spacing $(P$ value $=0.55)$ and crossbite $(P$ value $=0.56)$. There was significant relationship found with malnutrition with dental caries and salivary flow $(P$ value $=0.003)$ in subjects as compared to other individuals. Also there was significant relationship present between enamel hypoplasia and malnutrition $(P$ value $=0.02$ ) of the subjects.

Conclusion: The present study shows no significant relationship of malnutrition with malocclusion, dental crowding, spacing and dental crossbite. Also there was significant value present to evaluate the relationship with malnutrition with dental caries, salivary flow rate and enamel hypoplasia.
\end{abstract}

Keywords: Dental Caries, Enamel Hypoplasia, Malnutrition, malocclusion, Mixed Dentition Stage, salivary gland flow.

\section{Introduction}

Malnutrition is a multifactorial disease that can occur in an early onset during intrauterine life or childhood or can occur during an individual's lifetime as a result of poor nutrition or repeated episodes of infectious or chronic diseases. ${ }^{2}$ Hence relationship between malnutrition and oral health has recently become a subject of study. Evidence suggests that protein energy malnutrition is associated with impaired growth and development of facial bones.

Protein-energy malnutrition (PEM) occurs when there are deficiencies in protein, energy foods or both, relative to a body's needs. Dietary energy and protein deficiencies can occur together. There are three type of nutrition deficiency as, mild PEM has an acute course and has a main deficiency in energy; moderate PEM is chronic in nature and has a main deficiency in protein, while severe PEM is both chronic and acute, and is composed of deficiencies in both protein and energy.

It is believed therefore that malnutrition may also be associated with malocclusion, which is defined as misalignment of the teeth due to insufficient space for them to erupt in the correct place. Altered bone growth in the craniofacial complex caused by poor nutrition could be reflected in reduced space for dental eruption. ${ }^{2}$

Dental crowding can be described as the relationship between tooth size and jaw size, which results in displacement of teeth. The reason could be large teeth or small jaw size or combination of both. Dental spacing is depended on the adjacent teeth, present in dental arch and their status. Crossbite are defined as any abnormal buccal-lingual relation between opposing incisors, molars, or premolars in centric relation. If the mid-lines undergo a compensatory or habitual shift when the teeth occlude in crossbite, this is termed a functional shift. A crossbite can be of dental or skeletal origin or a combination of both.

Abnormalities of enamel can occur due to environmental forces, hereditary or can be idiopathic in nature. Dental Enamel is unique structure and remodeling of enamel does not occur after it is formed, therefore any abnormalities occurs during formation is permanently on the tooth surface. Enamel hypoplasia (EH) occurs in the form of pits, grooves or large areas of missing enamel. Usually appears bilaterally on teeth. Saliva is the complex mixture of fluids that surrounds the oral tissues, and it originates from major and minor salivary glands. The consistency of saliva can be watery, thick, sticky or frothy depending on its composition; the amount of proteins in saliva mainly will determine its thickness or frothiness. ${ }^{5}$

Dental caries is characterized by localized, microbial infectious process that ends up in the destruction of hard dental tissue. Many factors which can cause dental caries are - poor oral hygiene, decreased salivary 
flow, more cariogenic diet, reduced number of fluoride in drinking water etc.The oral cavity is the doorway through which the body receives and processes nourishment. Multiple oral tissues like oral mucosa, teeth and periodontal tissues work together and are no less susceptible to nutritional stresses. The importance of this study becomes evident when considering high prevalence of malnutrition and its relationship with various abnormal oral findings in mixed dentition stage.

\section{Material And Methods}

- Study sample:

One hundred twenty subjects based on eligibility criteria and who were willing to participate were reported for this clinical study. The study was carried out in the Rabindranath Tagore Medical College \& hospital, Udaipur, Rajasthan.

- Inclusion criteria:

$>$ Children from age 6 to 12 years.

$>$ Malnourished children.

$>$ Children without any unstable mental or physical condition.

$>$ Children not under any medication.

- Exclusion criteria:

$>$ Children or parents not willing to participate.

Demographic data including age, sex were obtained from, parents prior to anthropometric measurements. Height was measured using stadiometer and weight using manual weighing machine. BMI was calculated according to following formula:- Weight in KG/ (Height in Meters) ${ }^{2}$. Finally dental examination was carried out in which DMFT indices were recorded in accordance with WHO criteria. Oral examination was carried out to check for Enamel hypoplasia. Salivary flow was checked with the help of oral Schirmer's test.

- Collection of data:

Children were then classified into three categories using age criteria. Three groups were made:

1) Group I: Age group of 6 to 7 years

2) Group II: Age group of 8 to 9 years

3) Group III: Age group of 10 to 12 years

\section{Results}

A total of 120 children including boys and girls who met the criteria were statistically analyzed using SPSS version 15.0 statistical analysis software. Comparison was made between low BMI score subjects with the dental crowding (Table 1), spacing (Table 2) and crossbite (Table 3). In the present study no significant results among the dental crowding $(\mathrm{P}=0.79 \mathrm{NS})$, spacing $(\mathrm{P}=0.55 \mathrm{NS})$ and crossbite $(\mathrm{P}=0.56 \mathrm{NS})$ against malocclusion was noted. Comparison was also made between subjects with low BMI having dental caries and the salivary flow rate in oral cavity (Table 4). The results showed ( $\mathrm{P}=0.003 \mathrm{~S}$ ) significant relationship in dental caries and salivary flow rate in low BMI subjects as compared to other individuals. In the comparison with the low BMI score subject and enamel hypoplasia (Table 5) showed ( $\mathrm{P}=0.02 \mathrm{~S}$ ) significant relationship with the malnutrition and enamel hypoplasia.

\section{Discussion}

Nutrition has increasingly been recognized as a basic pillar for social and economic development and one of the main determinants of individual, family and community health. It is the science of how the body utilizes food or nutrients to meet requirements for development, growth, repair and maintenance. Nutritional status is a measurement of the extent to which an individual's defined physiological need for nutrients are being met by his or her dietary patterns and choices. Thus these measurements entail review of dietary intake, biochemical markers of nutrient status and anthropometric changes. ${ }^{14}$

The current study showed no significant relationship of malnutrition with dental crowding, spacing and dental crossbite. Similar to this study Thomas E. B. A. F. et al. evaluated that malnourished children having habit of thumb sucking showed dental crowding describing that the use of pacifiers decreases the occurrence of dental crowding. ${ }^{3}$ Thomas E. B. A. F. et al. studied the association of malnutrition and dental crowding, concluded that the subjects with malnutrition associated with habit of mouth breathing showed dental crowding ,describing the habit was associated with dental crowding.$^{2}$ Khan S. H. et al. compared dental crowding with malnutrition and showed no significant relationship, describing that the subjects with the habit showed dental crowding but other subjects didn't showed any significant relationship with malnutrition and malocclusion. ${ }^{7}$

In the present study, there was significant association of dental caries with the salivary flow rate as compared to other individuals. Similar to this study, Moynihan P. et al. described that the deficiency of PEM and vitamin A leads to affect the buffer capacity of the saliva which leads to dental caries ${ }^{8}$ and Xaviour A. et al. 
conducted similar study on nutrition with dental caries and stated the correlation between dental caries and nutrition of the patient that gave significant relationship. ${ }^{9}$ Shetty C. et al., Lukacs J. R. et al., Bagramian R. et al. conducted the study for salivary flow rate and dental caries showed significant relationship between dental caries and salivary flow rate. ${ }^{6,10,11}$

In current study, enamel hypoplasia was also evaluated for the association with the patients of low BMI score. The results showed correlation between the enamel hypoplasia and malnutrition. Similar to this study Yadav P. K. et al. described the association of dental caries with the enamel opacities. ${ }^{12}$ Basha S. et al. conducted the study on association between the developmental defects, dental caries and nutritional status of the subjects and concluded significant correlation between developmental defects and nutritional status.

The present study concludes that the hypothesis of malnutrition and its association with malocclusion has a negative correlation. Furthermore the malnourished subject showed significant relationship with dental caries and salivary flow rate when compared to normal subjects. Malnutrition when compared with enamel hypoplasia also showed significant relationship. Lastly, the theoretical model used in this study proved the little explanatory value, suggesting that other variables, such as genetic inheritance, need to be included in future multivariate analysis.

Tables

Table 1: Showing Association of Malnutrition and Dental Crowding with $\mathrm{P}$ value

Table 2: Showing Association of Malnutrition and Spacing with $\mathrm{P}$ value

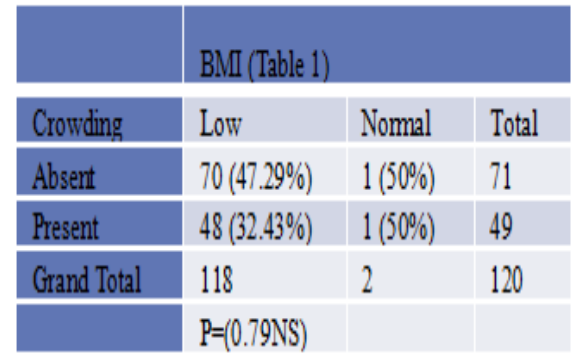

\begin{tabular}{|l|l|l|l|}
\hline & BMII (Table 2) & & \\
\hline Spacing & Low & Nomal & Total \\
\hline Absent & $82(69.49 \%)$ & $1(50 \%)$ & 83 \\
\hline Present & $36(30.50 \%)$ & $1(50 \%)$ & 37 \\
\hline $\begin{array}{l}\text { Grand } \\
\text { Total }\end{array}$ & 118 & 2 & 120 \\
\hline & P $=(0.55$ NS $)$ & & \\
\hline
\end{tabular}

Table 3: Showing Association of Malnutrition and Dental Crossbite with $\mathrm{P}$ value

Table 4: Showing association of salivary flow rate with dental caries in low BMI subjects and $P$ value

\begin{tabular}{|l|l|l|l|}
\hline & BMI (Table 3) & & \\
\hline Crossbite & Low & Nomal & Total \\
\hline Absent & $100(84.74 \%)$ & $2(100 \%)$ & 102 \\
\hline Present & $18(15.25 \%)$ & $0(0 \%)$ & 18 \\
\hline Grand Total & 118 & 2 & 120 \\
\hline & P $=(0.56 \mathrm{NS})$ & & \\
\hline
\end{tabular}

\begin{tabular}{|l|l|l|}
\hline & \multicolumn{2}{|l|}{ Dental Caries (Table 4) } \\
\hline $\begin{array}{l}\text { Salivary } \\
\text { function }\end{array}$ & Absert & Present \\
\hline & No. & No. \\
\hline Loir & 14 & 72 \\
\hline Normal & 12 & 23 \\
\hline High & 2 & 1 \\
\hline & $(\mathrm{P}=0.003 \mathrm{~S})$ & \\
\hline
\end{tabular}

Table 5: Showing association of Malnutrition with Enamel Hypoplasia and $\mathrm{P}$ value

\begin{tabular}{|l|l|l|}
\hline & \multicolumn{2}{|l|}{ BMI (Table 5) } \\
\hline $\begin{array}{l}\text { Enamel } \\
\text { Hypoplasia }\end{array}$ & Low & Normal \\
\hline Absent & 28 & 3 \\
\hline Present & 88 & 1 \\
\hline & $(\mathrm{P}=0.02 \mathrm{~S})$ & \\
\hline
\end{tabular}




\section{Conclusion}

In the present study, we used anthropometry based on W/A and H/A indices, as a criterion to classify exposition. Anthropometry has been used as the diagnostic method of choice for the assessment of nutritional status for populations.Even though in present study there was no significant result found between BMI score and malocclusion, a significant relationship was noted between dental caries, salivary flow rate and enamel hypoplasia. Hence it is reasonable to suggest that poor health and nutrition are related to dental caries, salivary flow rate and enamel hypoplasia. Therefore policy actions aimed at reducing low height for age and unhealthy oral habits are strongly recommended in order to reduce ill effects. Due to limited subjects in this study, further studies are needed to increase consistency of findings and improve understanding of the present subject.

\section{References}

[1]. Pstoer W.J., Reid B.C., Katz R. V. Malnutrition and Dental Caries: A review of literature. Caries Res.2005; 39(6):441-447.

[2]. Thomas E. B. A. F. et al. Is Malnutrition Associated with Crowding in Permanent Dentition? International Journal of Environment Research and Public Health.2010; 8: 3531-3544.

[3]. Thomas E. B. A. F., Valenca A. M. G. Relationship between childhood underweight and dental crowding in deciduous teething. Journal de Pediatria.2009;85(2):110-116

[4]. Gupta S. P., Shetty P. P., Reddy K., Sancheti P. Enamel Hypoplasia: A Case Report. Journal of Advanced Oral Research.2014;5(1):10-13.

[5]. Cunha-Cruz J., Scott J., Rothen M., Mancl L., Lowhorn T., Brossel K., Berg J. Salivary characteristics and dental caries: Evidence from general dental practices. J Am Dent Assoc.2013;144(5):31-40.

[6]. Shetty C., Hegde M. N., Devadiga D. Salivary characteristics and dental caries: Evidence from general dental practices. Int. J. Res. Ayurveda Pharm.2013;4(2):219-223.

[7]. Khan S. H., Hasan M. N., Anjum S., Rafique T. "Is there is any relationship between malocclusion and nutritional pattern of children". Updat Dent. Coll. J.2014;4(2):09-13.

[8]. Moynihan P., Peterson P. E. Diet, nutrition and the prevention of dental diseases. Public Health Nutrition.2004;7(1A):201-206.

[9]. Xaviour A., Bastos R. S., Arakawa A. M., Caldana M. L., Bastos J. R. M. Correlation between dental caries and nutritional status: preschool children in a Brazilian municipality. Rev Odontol UNESP.2013;42(5):378-383.

[10]. Lukas J. R., Largaespada L. L. Explaining Sex Differences in Dental Caries Prevalence: Saliva, Hormones, and “Life-History”, Etiologies. American Journal of Human Biology.2006;18:540-555.

[11]. Bragmian R. A., Godoy F. G., Volpe A. R. The global increase in dental caries. A pending public health crisis. American Journal of Dentistry.2009;21(1):4-8.

[12]. Yadav P. K., Saha S., Jagannath G. V., Singh S. Prevalence and Association of Developmental Defects of Enamel with, DentalCaries and Nutritional Status in Pre-School Children, Lucknow. Journal of Clinical and Diagnostic Research.2015;9(10):71-74.

[13]. Basha S., Mohamed R. N., Swamy H. S. Prevalence and Associated Factors to Developmental Defects of Enamel in Primary and Permanent Dentition. OHDM.2014;13(3):588-594

[14]. Vedi A., Goel R., Veeresha K. L., Sogi G. M., Swamy A. Oral Health \& Malnutrition-“The Missing Link”. International Journal of Advanced Research.2015;3(5):381-386. 